\title{
Cultivo do pimentão em condições protegidas sob diferentes doses de nitrogênio via fertirrigação
}

\author{
Jucilene S. Araújoㅁ, Alberício P. de Andrade ${ }^{2}$, Cícera I. Ramalho² \& Carlos A. V. de Azevedo ${ }^{3}$
}

\begin{abstract}
RESU MO
Com o objetivo de avaliar o efeito de doses de nitrogênio aplicadas via fertirrigação sobre o rendimento do pimentão cultivado em ambiente protegido, conduziu-se este trabalho no Centro de Ciências Agrárias-U FPB, consistindo de cinco tratamentos $\left(0,100,200,300\right.$ e $400 \mathrm{~kg} \mathrm{ha}^{-1}$ de $\left.\mathrm{N}\right)$ e 4 repetições. Avaliou-se o rendimento de frutos total, comercial e não-comercial e se determinou a relação entre a área foliar (AF) e 0 índice de área foliar (IAF) com o rendimento. Todas as doses de nitrogênio influenciaram, linear e positivamente, os rendimentos de frutos total e comercial e, de forma quadrática, o rendimento de frutos não-comercial. A acumulação térmica do pimentão para se atingir a fase de maior rendimento foi de $1,668^{\circ} \mathrm{C}$ e, para que completasse todo o seu ciclo fenológico, foram necessários 2,155 GDA. A área foliar e 0 índice de área foliar afetaram o rendimento total de frutos do pimentão, de forma linear.
\end{abstract}

Palavras-chave: capsicum annuum, nutrição de plantas, ambiente protegido

\section{Yield of bell pepper cultivated in greenhouse under different doses of nitrogen through fertirrigation}

\begin{abstract}
Aiming to evaluate the effect of doses of nitrogen applied via fertirrigation on the yield of bell pepper cultivated in greenhouse, this work was conducted at the Center of Agrarian Sciences - UFPB. The experiment consisted of five treatments $\left(0,100,200,300\right.$ and $400 \mathrm{~kg} \mathrm{ha}^{-1}$ of $\left.\mathrm{N}\right)$ and 4 repetitions. Total, commercial and non-commercial fruit yields were evaluated, and the relationship between the leaf area and the leaf area index with the yields were determined. The doses of nitrogen influenced linearly and positively the total (commercial plus non-commercial fruits) and for the commercial yield of fruits, and for non-commercial fruits of the bell pepper a quadratic function was observed. The thermal accumulation of the bell pepper to reach the phase of larger yield was of $1.668^{\circ} \mathrm{C}$, and to complete its whole phenologic cycle, 2.155 GDA were necessary. The leaf area and the leaf area index affected the total yield of fruits of bell pepper, in a linear and positive way. The leaf area index showed itself to be satisfactory for the conditions of this experiment, demonstrating that the density of the plants used was adequate.
\end{abstract}

Key words: Capsicum annuum, nitrogen manuring, greenhouse

1 INSA, Av. Floriano Peixoto 715, Centro, CEP 58100-001, Campina Grande, PB. Fone: (83) 2101-6412. E-mail: jucilenearaujo@insa.gov.br

2 CCA/U FPB, Campus II, C.P. 22, CEP 58397-000, Areia, PB. Fone: (83) 3362-2300, Fax: (83) 3362-2259. E-mail: al bericio@uol.com.br; isaramalho3@hotmail.com

3 UAEAg/UFCG, Av. Aprígio Veloso 882, Bodocongó, CEP 58109-970, Campina Grande, PB. Fone: (83) 3310-1056. E-mail: cazevedo@deag.ufcg.edu.br 


\section{INTRODUÇÃO}

A evolução da agricultura moderna é fundamentada na necessidade de se produzir mais visto que, com o crescente aumento da população, ocorre tendência de aumentar a disparidade entre a oferta e o consumo de alimentos. Para produzir mais foi imprescindível criar condições mais propícias para o desenvolvimento das plantas surgindo, então, os adubos, os defensivos, o melhoramento genético, o manejo de solo e a irrigação, dentre outros; além disso, havia o problema da sazonalidade climática, que permitia o cultivo apenas em alguns períodos do ano (Resende \& Gonçalves, 2004).

A tendência dessa agricultura é minimizar os riscos com a utilização intensiva de tecnologia, em que uma das formas de se fazer isto é através do cultivo protegido; trata-se de uma técnica amplamente consolidada em vários países do mundo (Sentelhas \& Santos, 1995); no Brasil, sua introdução ocorreu no final da década de 70, com trabalhos pioneiros, nos quais se utilizou o plástico em estruturas com a finalidade de proteção contra as adversidades climáticas (Goto, 1997). Esta tecnologia desponta como alternativa para os horticultores, haja vista que minimiza os efeitos da variabilidade ambiental, melhorando o desenvolvimento dos cultivos, permitindo a produção durante todo o ano alcançando, assim, maiores preços no mercado (Silva et al., 1999a); além de proteger a cultura dos efeitos negativos do vento, chuva e granizo, possibilita aumentos consideráveis na produtividade, também de precocidade, melhor qualidade e economia de insumos (Sganzerla, 1997; Gomes et al., 1999).

O pimentão (Capsicum annuum L.), solanácea de alto valor alimentício, está entre as hortaliças mais consumidas do Brasil, principalmente na região sudeste (Melo et al., 2000); em estufa, situa-se entre as cinco que apresentam maior área cultivada no Brasil e em diversos países, devido à grande produtividade e qualidade dos frutos que podem ser alcançadas nessas condições (Lorentz et al., 2002).

Cunha et al. (2002) constataram, em trabalho com pimentão, que o cultivo protegido foi mais eficiente na conversão da radiação líquida disponível em matéria seca total e na produtividade de frutos, além de menores perdas de energia, mostrando-se também mais eficiente no uso da água em relação ao cultivo em campo.

Para o desenvolvimento adequado da planta e obtenção de produtividade satisfatória, é essencial a reposição de água e nutrientes na quantidade ideal e no momento oportuno (Nanetti et al., 2000). O conhecimento de práticas agrícolas, como a adubação e seu efeito na nutrição mineral e na produção do pimentão, é necessário para que os produtores utilizem, racional e economicamente, os fertilizantes. No Brasil, em condições de cultivo protegido as publicações sobre adubação na cultura do pimentão são escassas (Melo et al., 2000).

O nitrogênio é um dos nutrientes mais extraídos pelas plantas de pimentão e altas doses são aplicadas em cobertura, parceladas em várias aplicações, visando reduzir as perdas por lixiviação e aumentar a eficiência de utilização do fertilizante; o excesso provoca desequilíbrio entre o crescimento da parte aérea em relação à porção radicular, aborto de flores, alongamento do ciclo vegetativo, maior sensibilidade a doenças (López, 1988) e menor produtividade (Locascio et al., 1981).

Dentre as tecnologias empregadas no cultivo protegido está a fertirrigação, ou seja, a aplicação de fertilizantes através da água de irrigação em que, sendo ela via gotejamento ou microaspersão, é a forma que mais se aproxima do ritmo de absorção de água e de nutrientes pela planta (Villas Boas et al., 2000).

No cultivo do pimentão em condições de campo, doses de até $224 \mathrm{~kg} \mathrm{ha}^{-1}$ de nitrogênio estiveram relacionadas com a alta produção de matéria seca e a produtividade (Locascio et al., 1985); em ambiente protegido doses de até $266 \mathrm{~kg} \mathrm{ha}^{-1}$ de nitrogênio na cultura do pimentão foram responsáveis pelo aumento na quantidade de nutrientes no caule, folhas e parte aérea, ao final do ciclo; entretanto, Silva et al. (2001) verificaram que a produção de frutos de pimentão não foi influenciada pela aplicação de nitrogênio (133, 266 e $399 \mathrm{~kg} \mathrm{ha}^{-1}$ ).

Em condições protegidas as plantas de pimentão têm maior crescimento vegetativo em relação ao campo aberto, principalmente em virtude da aplicação de quantidades elevadas de nitrogênio (Silva et al., 1999b), pois as condições de cultivo em ambientes protegidos são diferentes daquelas em campo a céu aberto, sobretudo com relação a perdas de nutrientes por erosão e lixiviação. Observa-se, então, que as recomendações existentes para o campo devem servir apenas como referenciais havendo, porém, necessidade de obtenção de informações específicas para este sistema de cultivo (Gomes et al., 1999) e em especial para a cultura do pimentão. A pesquisa brasileira na área de nutrição e adubação mineral deve ter, como propósito primeiro, a geração e expansão de conhecimentos sobre a nutrição e adubação de hortaliças em cultivo protegido visto que, neste ambiente, as doses e formas de aplicação de nutrientes devem ser diferenciadas em relação ao campo, de forma que a planta receba a quantidade ideal de fertilizantes evitando assim o desperdício e a salinização do solo, pois neste sistema não ocorrem chuvas, o que concorre para a salinização do solo. Com relação ao nitrogênio verifica-se, em geral, a extrapolação da recomendação da adubação nitrogenada no campo para o cultivo protegido; deve-se, entretanto, levar em consideração que o excesso desse nutriente provoca o desequilíbrio entre o crescimento da parte aérea em relação à porção radicular, aborto de flores, alongamento do ciclo vegetativo, maior sensibilidade a doenças e queda na produtividade, conforme Malavolta (1980), López (1988).

Neste sentido se propôs, com o trabalho, avaliar a produção de frutos de pimentão obtidos de plantas fertirrigadas com diferentes doses de nitrogênio e cultivadas em ambiente protegido.

\section{MATERIAL E MÉTODOS}

O trabalho foi conduzido nos meses de fevereiro a junho de 2004, no Centro de Ciências Agrárias-UFPB, município 
de Areia, PB, na Microrregião do Brejo Paraibano, a $60^{\circ} 58^{\prime} 12^{\prime}$ 'de Latitude Sul e $350^{\circ} 42^{\prime} 15^{\prime}$ ' de Longitude Oeste de Greenwinch, com altitude de aproximadamente 575 m (Gondim \& Fernandez, 1980). A precipitação pluviométrica média anual se situa em torno de $1400 \mathrm{~mm}$; a temperatura média anual oscila entre 23 a $24{ }^{\circ} \mathrm{C}$, com pequenas variações mensais (Brasil, 1972).

O delineamento experimental foi em blocos casualizados, com 5 tratamentos $\left(0,100,200,300\right.$ e $400 \mathrm{~kg} \mathrm{ha}^{-1} \mathrm{de}$ N) e 4 repetições; em cada parcela experimental com dimensões de 2,40 x 2,10 m $\left(5,04 \mathrm{~m}^{2}\right)$, se transplantaram mudas de pimentão, em dois pares de linhas paralelas, seguindo um modelo triangular, perfazendo o total de 18 plantas por parcela, distanciadas $50 \mathrm{~cm}$, sendo o espaço entre cada par de linhas de $80 \mathrm{~cm}$, sendo consideradas úteis as plantas das fileiras centrais.

Utilizou-se uma estufa plástica em arco, com $189 \mathrm{~m}^{2}$, altura na lateral livre $3,00 \mathrm{~m}$, coberta com filme plástico de 120 micras e fechamento lateral com tela para sombreamento de $30 \%$, plástico para "saia" com $40 \mathrm{~cm}$ de altura e cortinas móveis manuais para laterais e fundo.

$\mathrm{O}$ solo da área experimental foi classificado como Neossolo Regolítico Psamitico Típico, textura areia franca, cujas características químicas e físicas são apresentadas na Tabela 1.

Quando da preparação das parcelas fez-se uma adubação em fundação com esterco de bovino, na quantidade de $20 \mathrm{t} \mathrm{ha}^{-1}$, incorporado ao solo 10 dias antes do transplantio, de acordo com a recomendação laboratorial. Os resultados da análise química do esterco, foram: N: 14,53; P: 4,52 e $\mathrm{K}: 15,86 \mathrm{~g} \mathrm{~kg}^{-1}$; as doses de nitrogênio, segundo os tratamentos, foram aplicadas via fertirrigação e parceladas em sete aplicações a cada 10 dias; já o potássio recomendado $\left(120 \mathrm{~kg} \mathrm{ha}^{-1}\right)$ foi aplicado simultaneamente com o nitrogênio, também via fertirrigação e em todos os tratamentos, inclusive na testemunha. $\mathrm{O}$ fósforo não foi utilizado em virtude da alta quantidade presente no solo, visto que a área vinha sendo cultivada com outras hortaliças.

A variedade trabalhada foi a All Big, pertencente ao grupo conhecido como Cascadura, muito cultivada na região do Brejo Paraibano. O sistema de irrigação foi por gotejamento, em que cada fileira de planta foi irrigada com uma tubulação de distribuição contendo um gotejador por planta com vazão média de $4,0 \mathrm{~L} \mathrm{~h}^{-1}$. A irrigação foi feita com base na disponibilidade de água do solo, determinada pelo uso de tensiômetros nas parcelas, de forma a manter o conteúdo de água no solo em torno de $80 \%$ da água disponível; a dosa- gem de fertilizante foi $64,128,192$ e $256 \mathrm{~g}$ de uréia por aplicação, para as doses de 100, 200, 300 e $400 \mathrm{~kg} \mathrm{ha}^{-1}$ de $\mathrm{N}$, respectivamente. A água utilizada na irrigação provinha de um poço Amazonas e foi classificada como $\mathrm{C}_{1} \mathrm{~S}_{1}$.

Realizaram-se, durante o ciclo da cultura, quatro capinas manuais, para eliminar ervas daninhas e tutoramento para sustentação das plantas; nos tratos fitossanitários se aplicou inseticida e fungicida a fim de controlar o pulgão (Aphis spp.) e a cercosporiose (Cercospora melangena).

Os frutos foram classificados pelo tamanho, de acordo com as normas vigentes no Ministério da Agricultura (Brasil, 2001), da seguinte forma: comerciais (comprimento $\geq 60 \mathrm{~mm}$ e diâmetro $\geq 40 \mathrm{~mm}$ ) e não comerciais (comprimento $<60 \mathrm{~mm}$ e diâmetro < $40 \mathrm{~mm}$ ou alguns defeitos graves, tais como frutos murchos, deteriorados, malformados, com danos mecânicos, por doenças ou pragas); avaliou-se o rendimento de frutos total, comercial e não-comercial. O rendimento correspondeu à produção total de frutos de cada tratamento e os dados foram expressos em $\mathrm{Mg} \mathrm{ha}^{-1}$. Determinou-se a área foliar de todas as plantas consideradas úteis na parcela utilizando-se a equação: $\mathrm{AF}=\mathrm{K}+\mathrm{L}+\mathrm{C}$, em que $\mathrm{K}$, é o coeficiente de correlação de valor 0,60 recomendado por Tivelli et al. (1997), L, a largura da folha e C, o comprimento; determinou-se o índice de área foliar dividindose a área foliar pela área de solo ocupada pelas plantas, sendo o resultado expresso $\mathrm{em} \mathrm{cm}^{-2}$; realizou-se, ainda, o cálculo de graus-dias acumulados (GDA) e se utilizaram, para o referido cálculo, as temperaturas mínima (Tm) e máxima (TM) diárias, registradas por termohigrômetros instalados dentro e fora da estufa, com leituras diárias a cada duas horas com início às 6:00 $\mathrm{h}$ e término às $21: 00 \mathrm{~h}$ durante os estádios de desenvolvimento da cultura, através da equação: GDA $=[(\mathrm{TM}-\mathrm{Tm}) / 2]+(\mathrm{Tm}+\mathrm{Tb})($ Ometto, 1981), em que Tb é a temperatura basal mínima de crescimento, que foi considerada igual a $10{ }^{\circ} \mathrm{C}$ (Goto \& Tivelli, 1998).

Os resultados foram submetidos à análise de variância (pelo teste $\mathrm{F}$ a 5\% de probabilidade) e regressão, através do Software SISVAR (Sistema para Análises Estatísticas) desenvolvido pela Universidade Federal de Lavras.

\section{RESULTADOS E DISCUSSÃO}

A Tabela 2 apresenta a análise de variância e de regressão para rendimento total, comercial e não-comercial de frutos de pimentão cultivar All Big, em função das doses de nitrogênio aplicadas via fertirrigação.

Tabela 1. Atributos químicos e físicos do solo da área experimental a uma profundidade de $20 \mathrm{~cm}$

\begin{tabular}{|c|c|c|c|c|c|c|c|c|c|c|}
\hline \multicolumn{11}{|c|}{ Atributos químicos } \\
\hline \multirow{2}{*}{$\begin{array}{c}\mathrm{pH} \\
\left(\mathrm{H}_{2} \mathrm{O}\right)\end{array}$} & $\mathbf{P}$ & $\mathrm{K}^{+}$ & $\mathrm{Na}^{+}$ & $\mathrm{H}^{+}+\mathrm{Al}^{+3}$ & $\mathrm{Al}^{+3}$ & $\mathrm{Ca}^{+2}$ & $\mathrm{Mg}^{+2}$ & SB & CTC & M.O \\
\hline & \multicolumn{2}{|c|}{$\mathrm{mg} \mathrm{dm}^{-3}$} & \multicolumn{7}{|c|}{$\mathrm{cmol}_{\mathrm{c}} \mathrm{dm}^{-3}$} & $g \mathrm{dm}^{-3}$ \\
\hline 6,2 & 184,43 & 26,10 & 0,07 & 0,25 & 0,00 & 2,65 & 1,50 & 4,29 & 4,54 & 5,28 \\
\hline \multicolumn{11}{|c|}{ Atributos físicos } \\
\hline Areia grossa & Areia fina & Silte & Argila & $\begin{array}{c}\text { Argila } \\
\text { dispersa }\end{array}$ & $\begin{array}{l}\text { Densidade } \\
\text { do solo }\end{array}$ & $\begin{array}{c}\text { Densid. } \\
\text { de partículas }\end{array}$ & $\begin{array}{l}\text { Porosidade } \\
\text { total }\end{array}$ & \multicolumn{2}{|c|}{ Umidade $\mathbf{g ~ k g}^{-1}$} & $\begin{array}{c}\text { Água } \\
\text { disponível }\end{array}$ \\
\hline & & $\mathrm{g} \mathrm{kg}^{-1}$ & & & \multicolumn{3}{|c|}{$\mathrm{kg} \mathrm{dm}^{-3}$} & $0,01 \mathrm{MPa}$ & $1,5 \mathrm{MPa}$ & $\mathrm{g} \mathrm{kg}^{-1}$ \\
\hline 616 & 235 & 119 & 30 & 25 & 1,53 & 2,74 & 0,44 & 99 & 30 & 69 \\
\hline
\end{tabular}


Tabela 2. Análise de variância e de regressão para rendimento total (RT), comercial (RC) e não-comercial (RNC) de frutos de pimentão cultivar All Big, em função das doses de nitrogênio

\begin{tabular}{|c|c|c|c|c|}
\hline \multirow{2}{*}{\multicolumn{2}{|c|}{ 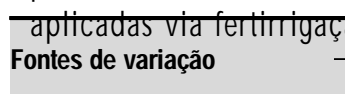 }} & \multicolumn{3}{|c|}{$\overline{Q M}$} \\
\hline & & \multirow{2}{*}{$\begin{array}{l}\text { RT } \\
62,010^{\text {NS }}\end{array}$} & \multirow{2}{*}{$\begin{array}{c}\text { RC } \\
68,119^{\text {NS }}\end{array}$} & \multirow{2}{*}{$\begin{array}{l}\text { RNC } \\
0,171^{\text {NS }}\end{array}$} \\
\hline Blocos & 3 & & & \\
\hline Níveis de N & 4 & $497,124^{* *}$ & $396,174^{* *}$ & $4,957^{\mathrm{NS}}$ \\
\hline Linear & 1 & $1880,190 * *$ & $1494,874 * *$ & $13,421^{* *}$ \\
\hline Quadrática & 1 & $50,692^{\mathrm{NS}}$ & $45,0904^{\text {NS }}$ & $5,350 * *$ \\
\hline Resíduo & 12 & 41,11 & 38,0185 & 0,144 \\
\hline$\overline{\mathrm{CV}}(\%)$ & & 19,92 & 21,32 & 11,88 \\
\hline
\end{tabular}

Os rendimentos de frutos total (comercial + não-comercial) (Figura 1A) e comercial (Figura 1B) aumentaram $(\mathrm{P}<0,01)$ com as doses de nitrogênio aplicadas, enquanto o rendimento de frutos não-comercial diminuiu $(\mathrm{P}<0,01)$ a partir da dose de $303 \mathrm{~kg} \mathrm{ha}^{-1}$ de nitrogênio (Figura 1C).

$\mathrm{O}$ rendimento total (Figura 1A), obtido com as doses de nitrogênio foi de $29,19 \mathrm{Mg} \mathrm{ha}^{-1}$ para a dose de $100 \mathrm{~kg} \mathrm{ha}^{-1}$, $33,06 \mathrm{Mg} \mathrm{ha}^{-1}$ para a dose de $200 \mathrm{~kg} \mathrm{ha}^{-1}, 38,45 \mathrm{Mg} \mathrm{ha}^{-1}$ para a dose de $300 \mathrm{~kg} \mathrm{ha}^{-1}$ e de $44,93 \mathrm{Mg} \mathrm{ha}^{-1}$ para a dose de $400 \mathrm{~kg} \mathrm{ha}^{-1}$. No município de Areia, PB, Leite Júnior (2001) obtiveram, trabalhando com a mesma variedade em condições de campo, rendimento total entre 4,65 e $18,4 \mathrm{Mg} \mathrm{ha}^{-1}$ demonstrando que, mesmo na menor dosagem, houve rendimento maior que o obtido pelos mencionados autores, nas condições em que foi desenvolvido o experimento.

O maior rendimento comercial (Figura 1B), 40,16 Mg ha ${ }^{-1}$, isto é, o que representa $89,4 \%$ da produção total, foi obtido na dose de $400 \mathrm{~kg} \mathrm{ha}^{-1}$ de nitrogênio; o incremento entre a testemunha ( $0 \mathrm{~kg} \mathrm{ha}^{-1}$ de nitrogênio) e a dose de $400 \mathrm{~kg} \mathrm{ha}^{-1}$ aproximou-se de $200 \%$. Batal \& Smittle (1981), enfatizam a importância da adubação nitrogenada no pimentão com a qual obtiveram rendimento de $26,4 \mathrm{Mg} \mathrm{ha}^{-1}$ na dose de $224 \mathrm{~kg} \mathrm{ha}^{-1}$ de nitrogênio. $\mathrm{O}$ fornecimento adequado de nitrogênio aliado a outros fatores como água, luminosidade, temperatura etc., expande a área fotossintética, assegura o desenvolvimento das plantas pelo crescimento vegetativo e eleva o potencial produtivo das culturas (Filgueira, 2000).

Do transplantio até a última colheita transcorreram 115 dias, durante os quais se realizaram oito colheitas nos tratamentos com nitrogênio e sete na testemunha. Leite Júnior (2001) trabalhando com a mesma variedade obteve, em condições de campo, o total de cinco colheitas, e Araújo (2005) seis colheitas; esta diferença entre o número de colheitas obtidas no experimento e o encontrado pelos referidos autores, deve estar associada à duração dos estádios fenológicos da cultura, que foi maior na estufa.

Obteve-se o rendimento máximo de frutos por colheita em todas as dosagens de nitrogênio $(100,200,300$ e $400 \mathrm{~kg} \mathrm{ha}^{-1}$ ), aos 88 dias após o transplantio (DAT); para a testemunha, este rendimento ocorreu aos 69 DAT (Figura 2) com redução nas colheitas seguintes, verificando-se que as plantas que não receberam adubação nitrogenada produziram, inicialmente, porém com o passar do tempo e com o aumento da necessidade desse nutriente, a produção foi inferior, o que demonstra que apenas o nitrogênio do

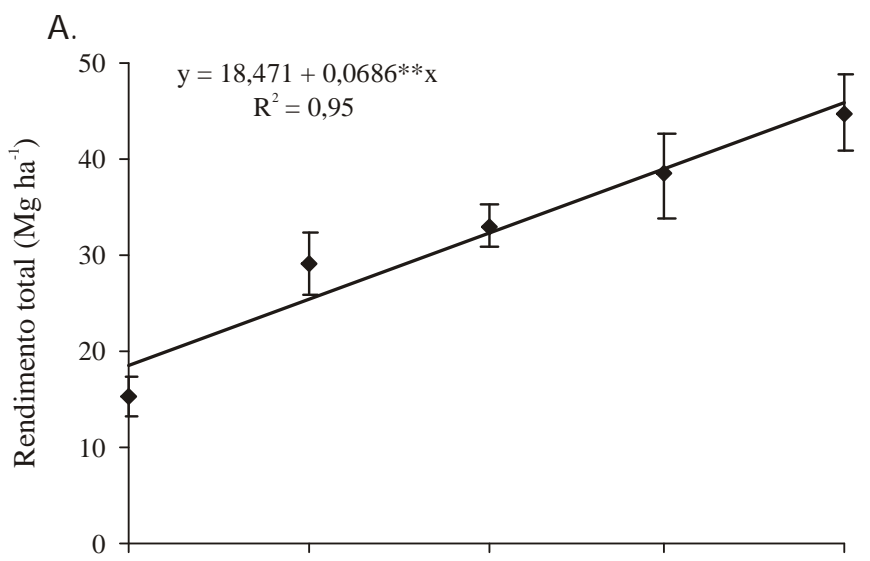

B.

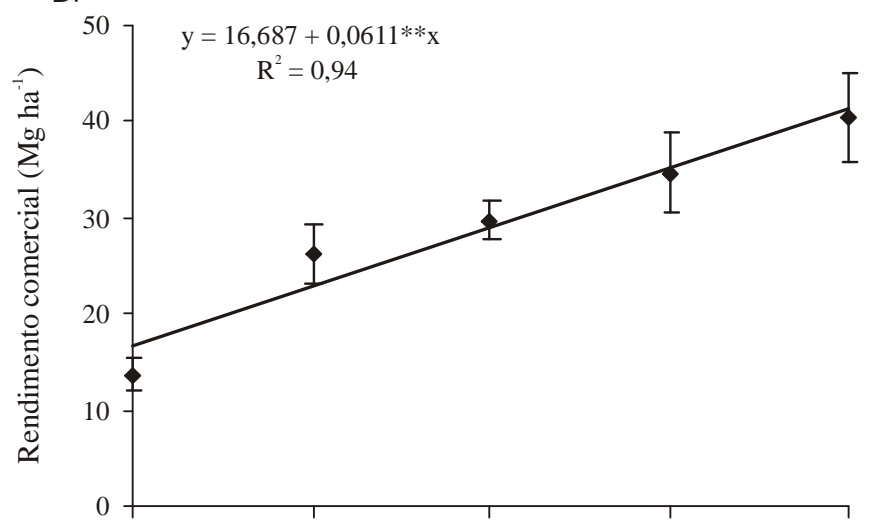

C.

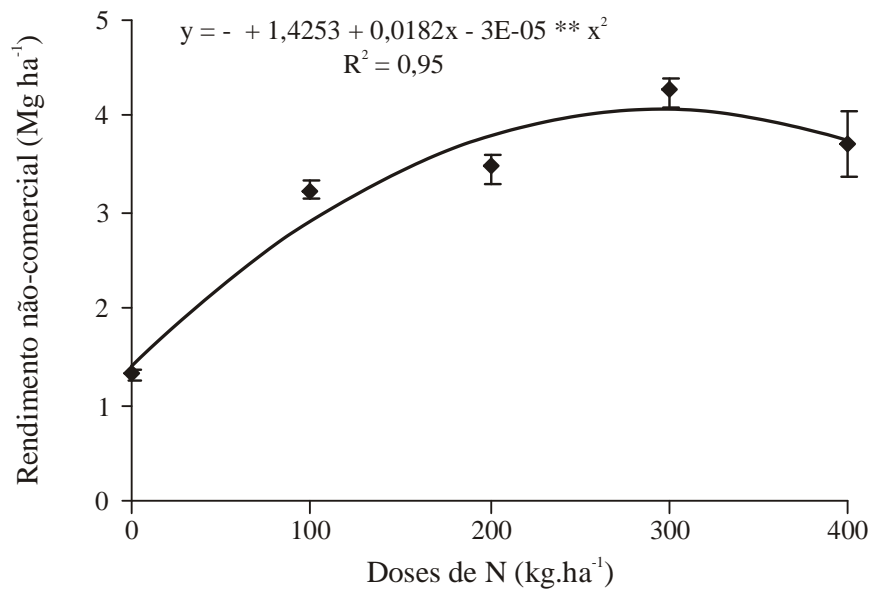

Figura 1. Rendimento total (A), comercial (B) e não-comercial (C) de frutos de pimentão, variedade All Big, em função das doses de nitrogênio aplicadas via fertirrigação; cada ponto representa a média de quatro repetições; as barras indicam o desvio padrão da média

solo não foi suficiente para promover aumento no rendimento da cultura no decorrer do experimento.

A diminuição do rendimento verificado precocemente na testemunha, é devida à ausência de adubação nitrogenada, o que pode ter ocasionado uma senescência maior das folhas neste tratamento, pois o aumento da senescência causa limitação no rendimento das culturas (Carlesso, 1993) e sua intensidade depende da quantidade de nitrogênio no solo, das reservas de nitrogênio na planta e da demanda pelos pontos de crescimento (Wolfe et al., 1988). 


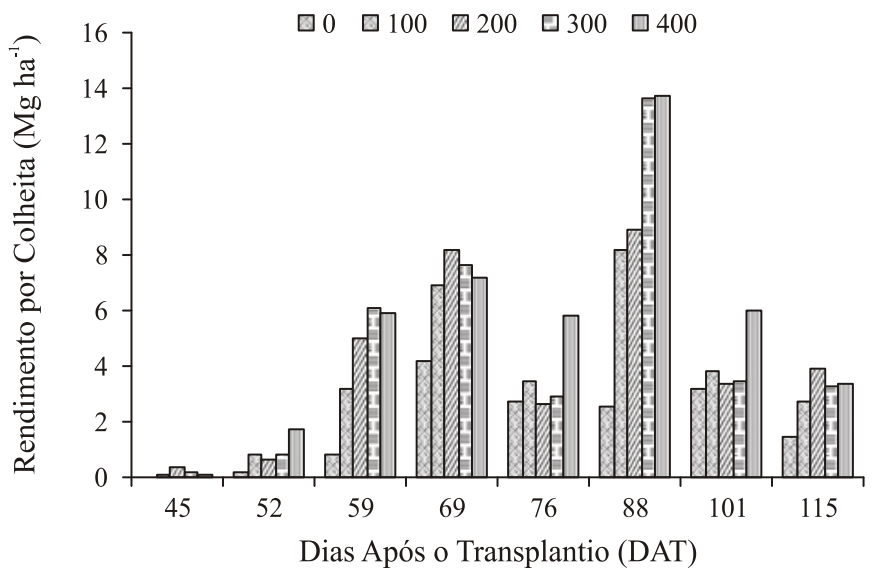

Figura 2. Rendimento por colheita de frutos de pimentão, variedade All Big, em função das doses de nitrogênio ( $\mathrm{kg} \mathrm{ha}{ }^{-1}$ )aplicadas via fertirrigação

Silva et al. (1999a) estudaram o rendimento de frutos de pimentão em ambiente protegido em função de nitrogênio e potássio aplicados em cobertura e notaram que a produção de frutos não foi influenciada pela adubação nitrogenada; por outro lado, Moreno et al. (1996), obtiveram um rendimento máximo de frutos total e comercial com doses maiores de nitrogênio.

$\mathrm{O}$ rendimento de frutos não-comerciais ajustou-se a um modelo quadrático $(\mathrm{P}<0,01)$ (Figura $1 \mathrm{C})$. Pela equação de regressão, constatou-se que a dose de $303 \mathrm{~kg} \mathrm{ha}^{-1}$ de nitrogênio foi a responsável pelo maior rendimento de frutos nãocomerciais, diminuindo na dose de $400 \mathrm{~kg} \mathrm{ha}^{-1}$.

$\mathrm{Na}$ falta de recomendações de adubação para cultivo em ambiente protegido, fazem-se adaptações da adubação realizada em campo aberto sendo que, na maioria das vezes, são fornecidas quantidades de nutrientes além daquelas exigidas pela cultura, caso em que se esperava que a dose máxima de nitrogênio $\left(400 \mathrm{~kg} \mathrm{ha}^{-1}\right)$ conduzisse a um efeito depressivo na cultura, por se tratar de uma dose além daquela recomendada com base na análise de laboratório; no entanto, este fato não ocorreu, já que o maior rendimento foi obtido com a referida dose.

Observa-se, na Tabela 3, a relação entre o rendimento de frutos por colheita e em função da quantidade de graus-dias acumulados (GDA) para o período transplantio-colheita. A acumulação térmica do pimentão para atingir a fase de maior rendimento foi de $1.668{ }^{\circ} \mathrm{C}$, ou seja, foram necessários 1.668 GDA para a cultura expressar o seu máximo rendimento, indicando que para anos diferentes a cultura pode ter $\mathrm{o}$ seu ciclo aumentado ou diminuído, o que vai depender da ocorrência da temperatura, que ocasionará maior ou menor acúmulo diário de graus-dias; do transplantio até o final das colheitas o número de GDA foi de $2.155^{\circ} \mathrm{C}$.

A relação entre a área foliar e o rendimento total da cultura pode ser observada na Figura 3A; o maior rendimento foi verificado quando as plantas atingiram o máximo de área foliar, permitindo a afirmação de que o rendimento de frutos de pimentão depende diretamente do crescimento da área foliar da planta; de acordo com Pereira \& Machado (1987) o rendimento da cultura será maior quanto mais rápido a planta atingir o índice de área foliar máximo e quanto mais
Tabela 3. Rendimento de pimentão por colheita e quantidade de graus-dias acumulados (entre parênteses), sob diferentes doses de nitrogênio, aplicadas via fertirrigação

\begin{tabular}{cllllr}
\hline DAT (GDA, $\left.{ }^{\circ} \mathbf{C}\right)$ & \multicolumn{5}{c}{ Dose de N (kg ha-1 } \\
\cline { 2 - 6 } & $\mathbf{0}$ & $\mathbf{1 0 0}$ & $\mathbf{2 0 0}$ & $\mathbf{3 0 0}$ & $\mathbf{4 0 0}$ \\
$45(873)$ & 0 & 0,13 & 0,39 & 0,16 & 0,12 \\
$52(1011)$ & 0,18 & 0,82 & 0,61 & 0,79 & 1,76 \\
$59(1145)$ & 0,78 & 3,21 & 5 & 6,11 & 5,95 \\
$69(1330)$ & 4,19 & 6,94 & 8,19 & 7,68 & 7,18 \\
$76(1463)$ & 2,76 & 3,45 & 2,6 & 2,94 & 5,79 \\
$88(1668)$ & 2,54 & 8,15 & 8,91 & 13,65 & 13,75 \\
$101(1903)$ & 3,21 & 3,81 & 3,39 & 3,47 & 5,97 \\
$115(2155)$ & 1,45 & 2,7 & 3,95 & 3,27 & 3,33 \\
\hline
\end{tabular}

tempo a área foliar permanecer ativa, já que a fotossíntese depende da área foliar.

O maior rendimento de frutos está associado ao fato das plantas com maior AF e, portanto, maior captação de luz terem, consequientemente, uma produção maior de assimilados, o que foi revertido em também maior rendimento (Andriolo, 1999). Segundo Galvani et al. (2000) em ambiente protegido e em dias de céu limpo as frações de irradiância difusa tendem a ser proporcionalmente maiores que em condições externas, devido à difusão pelo polietileno, possibilitando maior aproveitamento pela cultura, em razão do fato de se propagar em todas as direções não se limitando, portanto, às folhas superiores das plantas mas aumentando a eficiência fotossintética por toda a superfície de área foliar possibilitando, desta forma, um rendimento superior da cultura no ambiente de cultivo.
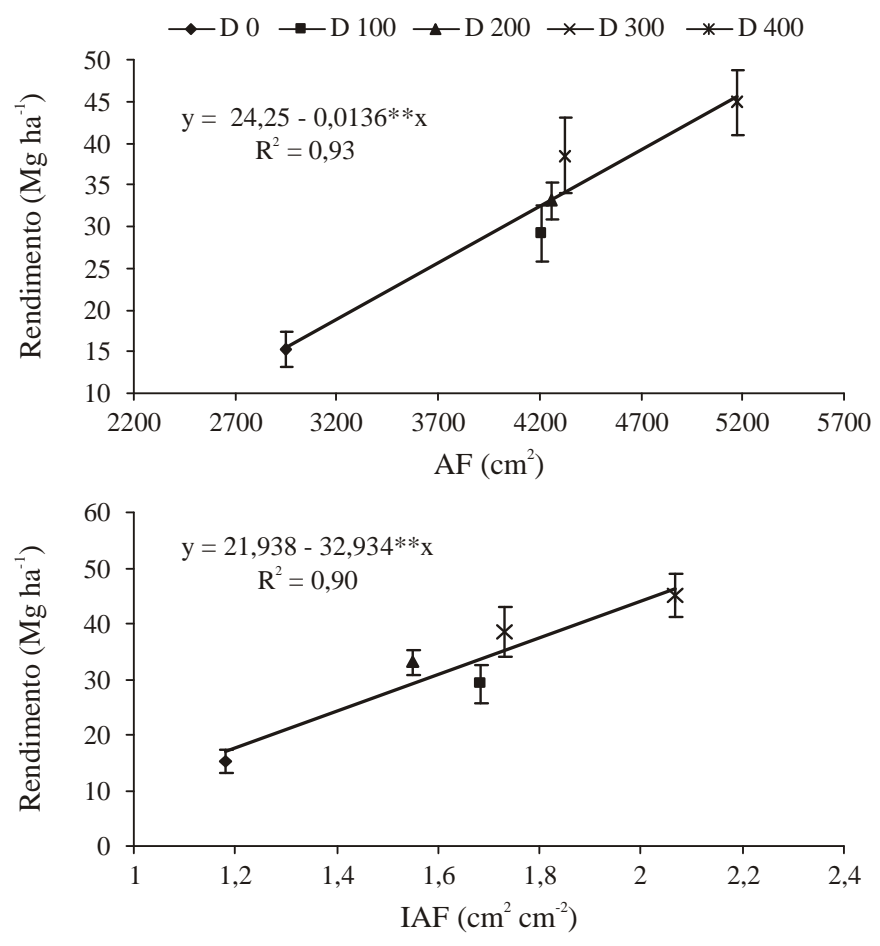

Figura 3. Relação entre o rendimento total e a área foliar (AF) e índice de área foliar (IAF) do pimentão, variedade All Big, em função das doses de nitrogênio aplicadas via fertirrigação; cada ponto representa a média de quatro repetições e as barras indicam o desvio padrão da média 
Observa-se na Figura 3B, que o rendimento de frutos aumentou com o índice de área foliar. Como se obteve bom rendimento de frutos e sendo sua relação com o índice de área foliar diretamente proporcional, é de se considerar que o IAF foi satisfatório para as condições deste experimento, demonstrando que a densidade de plantas usada foi adequada.

Como existe uma relação diretamente proporcional entre a área foliar (AF) e o índice de área foliar (IAF) com o rendimento da cultura e, ainda, como esses aumentaram com as doses de nitrogênio, supõe-se que houve uma maximização na produção de assimilados o que foi convertido em maior rendimento da cultura. Aliada a esses fatores, a aplicação do nitrogênio via fertirrigação deve ter proporcionado maior aproveitamento do nitrogênio aplicado em relação às perdas, já que este sistema de aplicação tem, como vantagem, o aumento da eficiência dos fertilizantes, pois se tem a possibilidade de repor os nutrientes na quantidade ideal e no momento oportuno (Nanetti et al., 2000). Zanini et al. (1995) ao estudarem os efeitos da freqüência de aplicação de nitrogênio e potássio via fertirrigação no pimentão, variedade Magda, verificaram redução no tempo de florescimento, aumento na produtividade $(12,7$ para $24,5 \mathrm{Mg} \mathrm{ha}^{-1}$ ) e maior qualidade dos frutos em comparação com a adubação convencional.

\section{CONCLUSÕES}

1. Os rendimentos de frutos total e comercial do pimentão foram influenciados, linear e positivamente, pelas doses de nitrogênio.

2. O rendimento de frutos por planta não-comercial foi influenciado pelas doses de nitrogênio, de forma quadrática, tendo o rendimento máximo ocorrido para a dose de $303 \mathrm{~kg} \mathrm{ha}^{-1}$.

3. A dose máxima de nitrogênio $\left(400 \mathrm{~kg} \mathrm{ha}^{-1}\right)$ promoveu um incremento no rendimento de frutos comerciais de aproximadamente $200 \%$, em relação à testemunha $\left(0 \mathrm{~kg} \mathrm{ha}^{-1}\right)$.

4. Foi necessário um acúmulo de 1.668 graus-dia para a cultura expressar seu máximo rendimento e, para que completasse todo o seu ciclo fenológico, 2.155 graus-dia.

5. A área foliar e o índice de área foliar afetaram o rendimento total de frutos do pimentão, de forma linear e positiva.

\section{LITERATURA CITADA}

Andriolo, J. L. Fisiologia das culturas protegidas. Santa Maria: UFSM, 1999. 142p.

Araújo, E. N. de. Rendimento do pimentão (Capsicum annuиm L.) adubado com esterco bovino e biofertilizante. Areia: UFPB, 2005. 75p. Dissertação Mestrado

Batal, K. M.; Smittle, D. A. Response of bell pepper to irrigation, nitrogen and plant population. Journal American Society for Horticultural Science, v.106, n.3, p.259-262, 1981.
Brasil. Ministério da Agricultura. Levantamento exploratório: Reconhecimento de solos do Estado da Paraíba. Rio de Janeiro: MA/SUDENE, 1972. p.669-670. (Boletim Técnico, 15)

Brasil. Ministério da Agricultura. Legislação aplicada à agricultura: Classificação de produtos vegetais. Artigo $3^{\circ}$ : Classificação do pimentão. http://agridata.mg.gov.br/legislacao/classificacao_cer.../laclassprodvegetalpimentao.nt. 27 Set. 2001.

Carlesso, R. Influence of soil water deficits on maize growth and leaf area adjustments. East Lansing: Michigan State University, 1993. 275p. Tese Doutorado

Cunha, A. R. da; Escobedo, J. F.; Klosowski, E. S. Estimativa do fluxo de calor latente pelo balanço de energia em cultivo protegido de pimentão. Pesquisa Agropecuária Brasileira, v.37, n.6, p.735-743, 2002.

Filgueira, F. A. R. Novo manual de olericultura: Agrotecnologia moderna na produção e comercialização de hortaliças. Viçosa: UFV, 2000. 402p.

Galvani, E.; Escobedo, J. F.; Cunha, A. R. da; Klosowski, E. S. Estimativa do índice de área foliar e da produtividade de pepino em meio protegido - cultivos de inverno e de verão. Revista Brasileira de Engenharia Agrícola e Ambiental, v.4, n.1, p.8-13, 2000.

Gomes, L. A. A.; Silva, E. C. da; Faquin, V. Recomendações de adubação em ambientes protegidos. In: Comissão de Fertilidade do Solo do Estado de Minas Gerais. Recomendações para uso de corretivos e fertilizantes em Minas Gerais: 5a Aproximação. Viçosa, 1999. 360p.

Gondim, A. W. A.; Fernandez, B. Probabilidade de chuvas para o município de Areia-PB. Agropecuária Técnica, v.1, n.1, p.55-63, 1980.

Goto, R. Plasticultura nos trópicos: Uma avaliação técnico-econômica. Horticultura Brasileira, v.15, p.163-165, 1997. Suplemento

Goto, R.; Tivelli, S. W. Produção de hortaliças em ambiente protegido: Condições subtropicais. São Paulo: UNESP, 1998. 319p.

Leite Júnior, G. P. Redução ou aumento das doses de nitrogênio e potássio aplicadas ao pimentão via fertirrigação à adubação convencional. Areia: UFPB, 2001. 65p. Dissertação Mestrado

Locascio, S. J.; Fiskell, J. G. A.; Graetz, P. A.; Hauck, R. D. Nitrogen accumulation by pepper as influenced by mulch and time of fertilizer application. Journal American Society for Horticultural Science, v.110, p.315-318, 1985.

Locascio, S. J.; Fiskell, J. G. A.; Martin, F. G. Responses of bell pepper to nitrogen sources. Journal of the American Society for Horticultural Science, v.106, p.628-632, 1981.

López, C. C. Fertilización en riego por goteo de cultivo horticolas. Madrid: Delegación de Agricultura Almeria Rafael Jimenes Mijias, 1988, 213p.

Lorentz, L. H.; Lúcio, A. D.; Heldwein, A. B.; Souza, M. F.; Mello, R. M. Estimativa da amostragem para pimentão em estufa plástica. Horticultura Brasileira, v.20, n.2, 2002. 4p.

Malavolta, E. Elementos de nutrição mineral de plantas. São Paulo: Ceres, 1980. 254p.

Melo, S. C.; Pereira, H. S.; Vitti, G. C. Efeitos de fertilizantes orgânicos na nutrição e produção do pimentão. Horticultura Brasileira, v.18, n.3, p.200-203, 2000. 
Moreno, D. A.; Pulgar, G.; Víllora, G.; Romero, L. Effect of N and $\mathrm{K}$ on fruit production and leaf levels of $\mathrm{Fe}, \mathrm{Mn}, \mathrm{Zn}, \mathrm{Cu}$ and $\mathrm{B}$ and their biochemical indicator in capsicum plants. Phyton, v.59, n.1-2, p.1-12, 1996.

Nanetti, D. C.; Souza, R. J. de; Faquin, V. Efeito da aplicação de nitrogênio e potássio, via fertirrigação, na cultura do pimentão. Horticultura Brasileira, v.18, p.843-845, 2000.

Ometto, J. C. Bioclimatologia vegetal. São Paulo: Agronômica Ceres, 1981. 440p.

Pereira, A. R.; Machado, E. C. Análise quantitativa do crescimento de comunidade vegetal. Campinas: Instituto Agronômico de Campinas, 1987. 33p. Boletim Técnico, 114

Resende, L. V.; Gonçalves, W. M. Cultivo de hortaliças em estufas: Quando plantar? <http://www.snagricultura.org.br/artigos/ artitec-horicultura01.htm>. 10 Jun. 2004.

Sentelhas, P. C.; Santos, A. O. Cultivo protegido: aspectos microclimáticos. Revista Brasileira de Horticultura Ornamental, v.1, n.2, p.108-115, 1995.

Sganzerla, E. Nova agricultura: A fascinante arte de cultivar com os plásticos. 6.ed. Guaíba: Agricultura, 1997. 342p.

Silva, M. A. G.; Boaretto, A. E.; Fernandes, H. G.; Boaretto, R.; Melo, A. M. T.; Scivittaro, W. B. Características químicas de um Latossolo adubado com uréia e cloreto de potássio em ambiente protegido. Scientia Agricola, v.58, n.3, p.561-566, 2001.
Silva, M. A. G.; Boaretto, A. E.; Melo, A. M. T. de; Fernandes, H. M. G.; Scivittaro, W. B. Rendimento e qualidade de frutos de pimentão cultivado em ambiente protegido em função do nitrogênio e potássio aplicados via fertirrigação. Scientia Agricola, v.56, n.4, 1999a. Suplemento.

Silva, W. L. C.; Carrijo, O. A.; Marouelli, W. A. Fertirrigação na Embrapa Hortaliças. In: Folegatti, M. V. (coord.) Fertirrigação: Citrus, flores, hortaliças. Guaíba: Agropecuária, 1999b. cap.5, p.433-440.

Tivelli, S. W.; Mendes, F.; Goto, R. Estimativa da área foliar do pimentão (Capsicum annum L.) cv. Elisa conduzido em ambiente protegido. Horticultura Brasileira, v.15, 1997. Suplementos

Villas Boas, R. L.; Kano, C.; Lima, C. P.; Nanetti, F. A.; Fernandes. D. M. Efeito de doses de nitrogênio aplicado de forma convencional e através da fertirrigação na cultura do pimentão. Horticultura Brasileira, v.18, p.801-802, 2000. Suplemento

Wolfe, D. W.; Henderson, D. W.; Hsiao, T. C. Interactive water and nitrogen effects on senescence of maize: 1. Leaf area duration, nitrogen distribution, and yield. Agronomy Journal, v.80, p.859-864, 1988.

Zanini, J. R.; Souza, E. C. A. de; Pavani, L. C.; Pancario, A. P. Efeitos da freqüência de aplicação da fertirrigação nitrogenada e potássica via irrigação por gotejamento na cultura do pimentão (Capsicum annuum L. cv. Magda). In: Congresso Brasileiro de Engenharia Agrícola, 24, 1995, Viçosa. Anais... Viçosa: CONBEA/SBEA, 1995. CD Rom 